\title{
Activação C-H por via organometálica
}

\section{CARLOS C. ROMÃO*}

\section{DEFINIÇÃo, ÂMBITO E INTERESSE}

As ligações C-H são das ligações químicas mais fortes e menos reactivas, permanecendo inertes perante um número muito elevado de reagentes e condições reaccionais. Todavia, 0 grande interesse prático das suas possiveis transformações tornou a chamada activação $\mathrm{C}$-H num tema importante da química orgânica, inorgânica e bioquímica, com particular ênfase na última década.

Na essência, a activação C-H é uma reacção ou passo reaccional que provoca a cisão desta ligação, eq.(1):
Embora não se possam considerar organometálicos e estejam, por isso, fora do contexto do presente artigo, os processos gerais de activação $\mathrm{C}-\mathrm{H}$ das eqs. (3) e (4) merecem, pela sua importância, uma breve referência. No processo descrito na eq. (3), a coordenação do metal a uma espécie $X$ produz um complexo altamente reactivo, capaz de activar a ligação $\mathrm{C}-\mathrm{H}$ num passo posterior, sem formação de ligações M-C. Este processo é oriundo da bioquímica existindo em diversos metalo-enzimas dos quais o mais conhecido é 0 citocromo $P$ 450. Este metalo-enzima de $\mathrm{Fe}$, existente

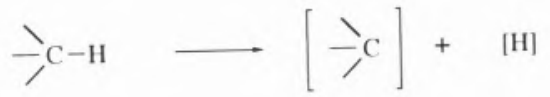

$$
\begin{aligned}
& \mathrm{L}_{\mathrm{n}} \mathrm{M}+\underset{\mathrm{C}}{-} \mathrm{C}-\mathrm{H} \longrightarrow \mathrm{L}_{\mathrm{n}} \mathrm{M}-\mathrm{C} \frac{\prime}{-}+[\mathrm{H}]
\end{aligned}
$$

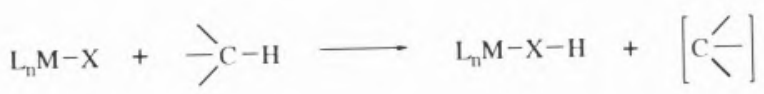

$$
\begin{aligned}
& \mathrm{L}_{\mathrm{n}} \mathrm{M}+\mathrm{X}-\mathrm{Y} \longrightarrow \mathrm{L}_{\mathrm{n}} \mathrm{M}-\mathrm{X}+[\mathrm{Y}] \\
& {[\mathrm{Y}]+\underset{\mathrm{I}}{\mathrm{I}-\mathrm{H}} \longrightarrow \underset{\mathrm{I}}{\mathrm{I}} \mathrm{C}-\mathrm{Y}}
\end{aligned}
$$

no fígado, é responsável pelo metabolismo de várias ligações $\mathrm{C}-\mathrm{H}$ que são hidroxiladas aos respectivos alcoóis (Quadro 1, Z = 0). Diversos modelos inorgânicos (biomiméticos) deste enzima, como o complexo 1, de tetrafenilporfirina (TPP) e Fe ${ }^{\text {III }}$, têm sido preparados e estudados.

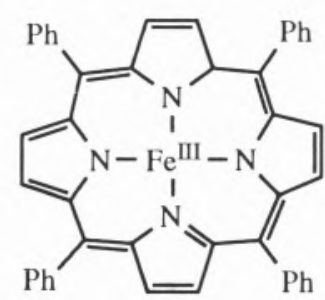
1

0 anel porfirínico (porf), independentemente dos seus substitutintes, é comum a todos estes compostos modelo mas outros metais como $0 \mathrm{Cr}$ e $0 \mathrm{Mn}$ podem também ser usados em lugar de Fe. As espécies activas destes compostos são os oxo complexos (porf)M=0 os quais podem ser originados por reacção com $\mathrm{O}_{2}$, ou outras substâncias capazes de doar átomos de 0 , nomeadamente $\mathrm{PhIO}$ e ROOH eqs.(5).

0 último tipo de activação, descrito em (4), é tipico dos processos de hidroxilação usados em química orgânica sendo 0 mais antigo 0 reagente de Fenton no qual um sal Fe ${ }^{\text {III }}$ decompõe a água oxigenada formando radicais $\mathrm{OH}$ que hidroxilam o hidrocarboneto, (6 ac). Vários processos semelhantes são
Na sua generalidade, esta definição omite a natureza dos reagentes que a promovem bem como o destino dos fragmentos dela resultantes os quais podem originar uma boa variedade de produtos, como se mostra no Quadro 1.

Entre os reagentes ou catalisadores necessários para a activação, os derivados de metais de transição desempenham um papel importante participando em processos de activação $\mathrm{C}-\mathrm{H}$ dos três modos representados nas equações (24) dos quais apenas o referido na eq. (2) é de natureza organometálica por conduzir à formação de ligações M-C.

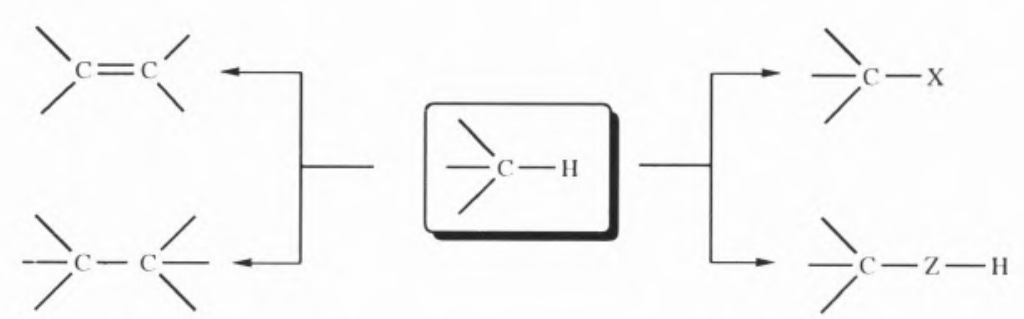

$\mathrm{Z} \equiv \mathrm{CO}, \mathrm{CO}_{2}, \mathrm{O}, \mathrm{S}$, etc. 


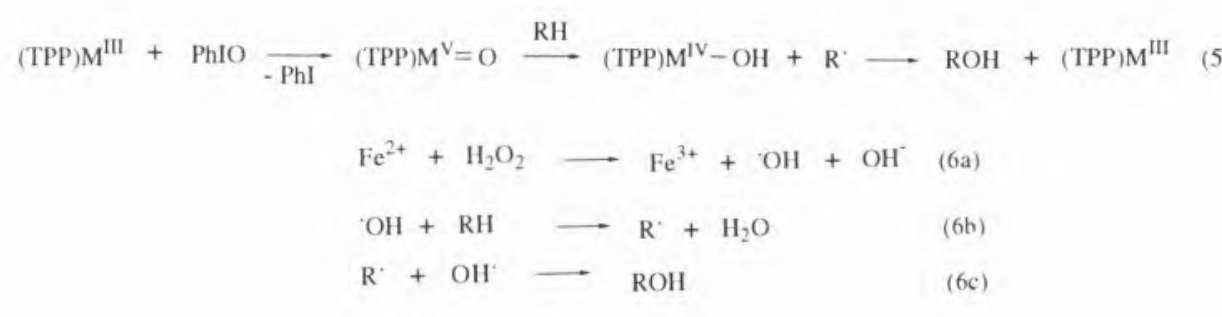

conhecidos em química orgânica (p. ex.

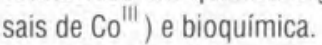

Devido à natureza radicalar dos processos descritos nas equações (3-6), a selectividade de ataque em ligações $\mathrm{C}-\mathrm{H}$ é a esperada com base na ordem decrescente de estabilidade dos radicais de hidrocarbonetos i.e., $3^{\circ}>2^{\circ}>1^{\circ}$. Mais recentemente, Barton desenvolveu um outro sistema de hidroxilações e oxidações, também baseado em sais de Fe e $\mathrm{O}_{2} .0$ mecanismo desta reacção ainda não é bem conhecido mas parece diferente do do reagente de Fenton devido à diferente selectividade que favorece a oxidação de grupos $\mathrm{CH}_{2}$ sobre grupos $\mathrm{CH}_{3}$ ou CH. ${ }^{1 \mathrm{~d}}$

Existem ainda outros processos de activação C-H de natureza organometálica. Todavia, pelo seu carácter radicalar, destacam-se do habitual campo de acção da química organometálica pelo que não serão abordados. Exemplos são a vitamina $B_{12} e$, importante pelas suas potenciais aplicações laboratoriais, a dimerização desidrogenativa de alcanos (vd Quadro 1) realizada por fotosensitização de vapores de $\mathrm{Hg} .^{1 \mathrm{1}}$

Como veremos, a natureza da activação $\mathrm{C}-\mathrm{H}$ por via organometálica não radicalar é diferente, invertendo a ordem de selectividade e tornando mais reactivas as ligações $\mathrm{C}\left(\mathrm{sp}^{3}\right)-\mathrm{H}$ primárias. Esta selectividade é especialmente interessante na medida em que permite a activação de qualquer hidrocarboneto, incluindo $\mathrm{CH}_{4}$, e não apenas dos que possuem ligações $\mathrm{C}-\mathrm{H}$ mais fracas ou mais reactivas quer iónica quer radicalarmente (ligações C-H activadas por substitutição no carbono). Do ponto de vista industrial, a activação $\mathrm{C}-\mathrm{H}$ pode constituir uma via alternativa para 0 acesso directo, a produtos e intermediários de interesse industrial, como alcoóis, ácidos carboxílicos, aldeídos, olefinas etc.(vd Quadro 1). Estratégicamente, esta alternativa é particularmente interessante se tivermos em conta a mudança que se tem processado nas matérias-primas da indústria química, a qual, após o domínio do acetileno nos anos 20-40 e do etileno nos anos 50-70, tende actualmente para a utilização de alcanos, a maior fonte de carbono orgânico existente na Terra.

A reutilização e consequente valorização dos resíduos de hidrocarbonetos acumulados pela sociedade industrial, dificilmente degradáveis e usados em tonelagens muito grandes, pode ser resolvida pelo mesmo tipo de química. A reciclagem de óleos pesados, de poliolefinas (polietileno e polipropileno) e de metano, (gás fortemente agravante do efeito de estufa) por transformação em produtos oxigenados, biodegradaveis, solúveis em água, ou outros reutilizáveis, seriam exemplos marcantes e de grande impacto económico e ambiental.

Do ponto de vista académico, o interesse é acrescido na medida em que a activação $\mathrm{C}-\mathrm{H}$ ainda é um desafio a vencer. Como veremos, ela é possivel mas ainda não tem expressão industrial pois os resultados obtidos sāo modestos em termos de reactividade e particularmente pobres no domínio, industrialmente decisivo, da funcionalização catalitica de hidrocarbonetos, principal objectivo a atingir.

Na referência 1 reunem-se os melhores textos gerais e de revisão sobre todos os aspectos da activação $\mathrm{C}-\mathrm{H}$ e suas aplicações. 0 livro de texto da referência 5 , ou qualquer outro em quimica organometálica e catálise homogénea, serão úteis para elucidar muitos outros aspectos da quimica organometálica referidos no texto. As referências da literatura primária são reduzidas às posteriores ao artigo de revisão de Crabtree (1985) peça fundamental neste domínio. ${ }^{1 \mathrm{c}}$

Já acima se aludiu à baixa reactividade da ligação $\mathrm{C}-\mathrm{H}$ particularmente evidente no caso dos alcanos que são das substâncias menos reactivas que se

\section{A BAIXA REACTIVIDADE DA LIGAÇÃO C-H: DIAGNÓSTICO E TERAPEUTICAS}

conhecem. Esta inércia reaccional resulta da conjugação de diversos factores como sejam: a inexistência quer de pares de electrões não partilhados (pnp) quer de orbitais vazias de baixa energia, a baixa polaridade da ligação $\mathrm{C}-\mathrm{H}$ e a forte energia de ligação (90-110 $\mathrm{Kcal} / \mathrm{mol}$ ). Estes dois últimos argumentos não serão certamente decisivos por si só pois a molécula de $\mathrm{H}_{2}$ também tem uma elevada energia de ligação e polaridade nula, sendo no entanto facilmente activada por metais de transição. ${ }^{2} 0$ diagrama de orbitais moleculares do $\mathrm{CH}_{4}$. esquematizado na Fig.1, revela, todavia a origem e importância dos dois primeiros argumentos.

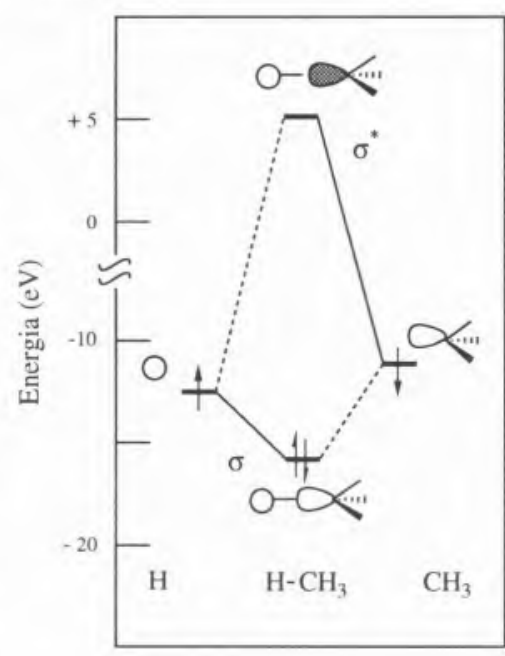

Figura 1. Diagrama de Orbitais Moleculares do $\mathrm{CH}_{4}$

Como se vê, a separação energética entre as orbitais ligantes e anti-ligantes é muito grande não existindo entre elas quaisquer orbitais não ligantes, quer cheias (pnp) quer vazias (LUMO de baixa energia), que confeririam à molécula propriedades nucleófilas ou electrófilas, respectivamente. Assim, um electrófilo apenas pode reagir com um alcano se atacar as orbitais ligantes, $\sigma \mathrm{C}$ - $\mathrm{H}$, retirando-Ihes densidade electrónica o que é evidentemente difícil dada a elevada estabilidade (baixa energia) dessas orbitais e o facto do lobo centrado no $\mathrm{C}$ ser estereoquimicamente bastante inacessivel por causa dos outros 3 substituintes. Por outro lado, a alta energia das orbitais vazias $\sigma^{*} \mathrm{C}-\mathrm{H}$ torna dificil a um nucleófilo ceder-Ihe (ou compartilhar) os seus electrões. A reactividade dos hidrocarbonetos (incluindo alcanos) face a superácidos e a sua relutância em reagir com 
nucleófilos (os alcanos não reagem) confirmam esta análise. Evidentemente, a acção cumulativa e simultânea destes dois efeitos facilitará a adição à ligação C-H como aliás se verifica na adição de carbenos singuleto a hidrocarbonetos.

Neste ponto, a comparação com 0 caso da activação de $\mathrm{H}_{2}$ é particularmente elucidativa da problemática existente $\mathrm{e}$ das soluções possiveis.

Na molécula de $\mathrm{H}_{2}$ também há uma grande separação entre os niveis $\sigma \mathrm{H}-\mathrm{H}$ e $\sigma^{*} \mathrm{H}-\mathrm{H}$, estando a energia de $\sigma \mathrm{H}-\mathrm{H}$ e de $\sigma^{*} \mathrm{H}-\mathrm{H}$ ambas um pouco abaixo da energia das orbitais $\sigma \mathrm{C}-\mathrm{H}$ e $\sigma^{*} \mathrm{C}-\mathrm{H}$, respectivamente. Por esta razão, embora se coordene mais dificilmente a um electrófilo ( $p$. ex. centro metálico) através da sua orbital preenchida $\sigma \mathrm{H}-\mathrm{H}$ (ligante), 0 $\mathrm{H}_{2}$ recebe mais facilmente electrões dum nucleófilo na sua orbital $\sigma^{*} \mathrm{H}-\mathrm{H}$ (antiligante). Este tipo de interacção com um fragmento $L_{n} M$ capaz de, simultâneamente, aceitar os electrões $\sigma \mathrm{H}-\mathrm{H}$ e doar electrões $d$ para a orbital $\sigma^{\star} \mathrm{H}-\mathrm{H}$, como esquematizado em 2 , resultará num enfraquecimento (menos electrões ligantes e mais electrões anti-ligantes) e eventual destruição da ligação $\mathrm{H}-\mathrm{H}$. Assim, dependendo do balanço doação $\sigma$ vs. aceitação $\pi$, existirá um contínuo de ângulos e distâncias entre as situações extremas 3 (complexo $\sigma, L_{n} M-\left(\eta^{2}-\right.$ $\left.\mathrm{H}_{2}\right)$ ) e 4 (dihidreto, $\mathrm{L}_{n} M \mathrm{H}_{2}$ ).

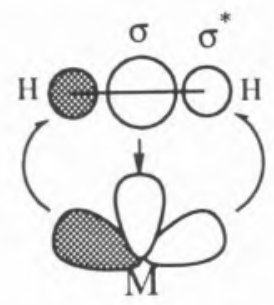

2

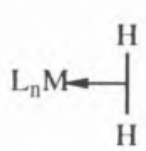<smiles>[Y1][H]</smiles>

3

4

Esta asserção tem sido experimentalmente confirmada num grande número de complexos de $\mathrm{H}_{2}$. A elevada acidez de Brönsted de muitos destes complexos, eq. (7), é também uma característica muito importante mesmo em casos em que $n=0$. $^{2}$

Lida de outro modo, a eq. (7) representa a cisão heterolítica do $\mathrm{H}_{2}$ activada por coordenação a um electrófilo.
Transpondo estes factos para a ligação C-H poder-se-ão estabelecer como estratégias para a sua activação: i) a adição oxidativa; ii) a activação electrófila com remoção de $\mathrm{H}^{+}$, tal como representadas no esquema 1.

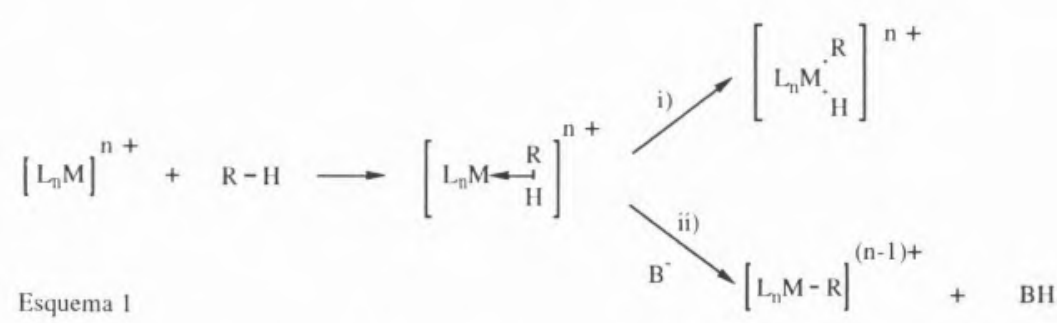

Ambas as estratégias implicam a formação de um complexo entre a ligação $\mathrm{C}-\mathrm{H}$ e 0 fragmento metálico. Se este tiver as orbitais de energia e simetria adequadas a uma forte rectrodoação para as orbitais $\sigma^{\star} \mathrm{C}-\mathrm{H}$ então ocorrerá a adição oxidativa. Se ele for essencialmente aceitador de electrões $\sigma \mathrm{C}-\mathrm{H}$, a remoção de $\mathrm{H}^{+}$conduzirá à cisão $\mathrm{C}-\mathrm{H}$. A esta via ii) chama-se activação electrófila e, de acordo com a natureza do metal, veremos que pode apresentar dois tipos de mecanismos: a activação electrófila propriamente dita e a metátese de ligações $\sigma$. Um ponto interessante sublinhado pelos cálculos teóricos, é o de que, ao contrário do caso da coordenação de $\mathrm{H}_{2}$, 0 mínimo de energia numa interacção entre $L_{n} M$ e C-H se observa para a espécie $L_{n} M-\left(\eta^{1}-C-H\right)$ e não $L_{n} M-\left(\eta^{2}-C-H\right)$ em virtude da repulsão estereoquímica entre $L_{n} M$ e os pares partilhados das outras ligaçōes $\mathrm{C}-\mathrm{H} .{ }^{1 \text { ta }}$

Perante este quadro aparentemente simples resta identificar os factores responsáveis pela dificuldade de obter exemplos claros de adição oxidativa do tipo i), tão frequentes na quimica do $\mathrm{H}_{2}$. Estes factores são de dois tipos: uns relacionam-se com os aspectos termodinâmicos e cinéticos da reacção, outros com a viabilidade da formação dos complexos $\sigma, L_{n} M-\left(\eta^{2}-C-H\right)$.
0 primeiro tipo de problemas foi abordado por estudos termoquímicos de energias de ligação $\mathrm{M}-\mathrm{C}$ e $\mathrm{M}-\mathrm{H},{ }^{3}$ e por estudos cinéticos sobre a reacção inversa, i.e., a eliminação redutiva representada pelo exemplo da eq. (8). ${ }^{4}$
Esta reacção é normalmente muito rápida e favorável o que se traduz pela existência de um número muito reduzido de complexos com ligandos hidreto e alquilo em posições cis (cis alquilo-hidreto). A facilidade desta eliminação redutiva é também um dos aspectos importantes dos mecanismos de hidrogenação catalítica de olefinas nos quais constitui o último passo regenerando a espécie catalíticamente activa e libertando 0 hidrocarboneto hidrogenado. ${ }^{5}$

No caso da eq.(8) a eliminação de $\mathrm{CH}_{4}$ é espontânea e exotérmica a $-20^{\circ} \mathrm{C} \mathrm{e}$ tem uma baixa energia de activação. De acordo com o princípio da reversibilidade microscópica, a adição oxidativa também deverá ter uma baixa barreira de activação pelo que será de esperar que a reacção esteja sob controle termodinâmico 0 qual dependerá do balanço da energia das ligações formadas e quebradas no processo e da energia do fragmento $L_{n} M$, eq. (9). Na maioria dos complexos de metais de transição, a energia das ligações $\mathrm{M}-\mathrm{C}, \mathrm{M}-\mathrm{H}$ e C-H é de cerca de 30,60 e $100 \mathrm{Kcal} / \mathrm{mol}$, respectivamente, o que torna a eliminação redutiva termodinâmicamente favorável no geral $(\Delta \mathrm{G}<0)$.

$$
\begin{aligned}
& {\left[\mathrm{L}_{n} M \underset{H}{\stackrel{H}{H}}\right]^{\mathrm{H}+} \stackrel{\mathrm{B}^{-}}{\longrightarrow}\left[\mathrm{L}_{\mathrm{n}} \mathrm{M}-\left.\mathrm{H}\right|^{(\mathrm{n}-1)+}+\mathrm{BH}\right.}
\end{aligned}
$$

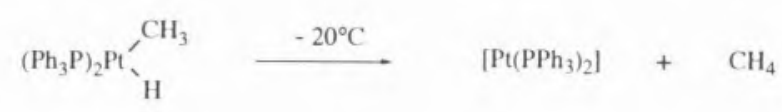


Para inverter a eq. (9), i.e., para favorecer a reaç̧ão de adição oxidativa, há que tornar 0 alquilo-hidreto estável maximizando a energia das ligações $\mathrm{M}-\mathrm{C}$ e $\mathrm{M}-\mathrm{H}$ e/ou desestabilizando 0 fragmento $L_{n} M$ (fragmento $L_{n} M$ de alta energia). Dentro dos metais de transição serão então mais reactivos os complexos da $3^{\mathrm{a}}$ série $(5 d)$ por possuirem maiores energias de ligação metalligando do que os da $1^{\underline{a}}$ e $2^{\text {a }}$ séries. 0 uso de fragmentos de elementos $d^{0}$ ou $f$ também permitirá obter energias de ligação $\mathrm{M}-\mathrm{C}$ e $\mathrm{M}-\mathrm{H}$ com valores acima da média dos metais de transição. ${ }^{3,4}$ Valores de $D\left(L_{n} M-C\right)+D\left(L_{n} M-H\right)>110$ $\mathrm{kcalmol}^{-1}$ já podem tornar termodinâmicamente mais favorável a reacção inversa de (9). Um reforço das ligações M-C resulta também do baixo impedimento estereoquímico de $L_{n} M$, pois tem sido demonstrado experimentalmente que a energia da ligação $\mathrm{M}$-C é claramente dependente da pressão estereoquímica em torno do elemento central.

No que se refere à viabilidade de formação do complexo $\sigma$, a resposta afirmativa foi sendo dada através da acumulação de dados sobre as chamadas ligações agósticas. Este termo, que em grego clássico significa agarrar-se a si

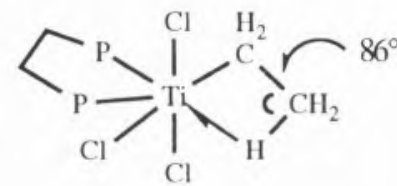

5

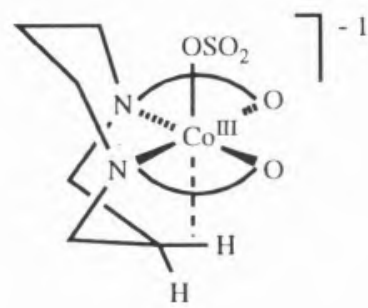

7

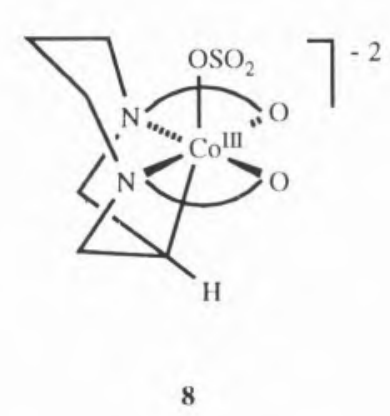

8

mesmo, foi proposto por Green e Brookhart para descrever as ligações C$\mathrm{H}$ altamente distorcidas que se vinham identificando em cada vez maior número por espectrocopia de infra-vermelho (IV) e ressonância magnética nuclear (RMN) e, especialmente, nas estruturas obtidas por difracção de raios- $X$ e neutrões. ${ }^{6}$

Alguns exemplos da Fig. 2 mostram 0 tipo de distorções observado. No composto 50 ângulo $\mathrm{C}-\mathrm{C}-\mathrm{H}$ de $80^{\circ}$ só pode ser explicado pela interacção agóstica entre $0 \mathrm{H}$ do grupo etilo e $0 \mathrm{Ti}$. Mais distorcido ainda é 0 ângulo $\mathrm{Ti}-\mathrm{C}-\mathrm{H}$ do grupo metilo do complexo análogo 6 . Estas distorções podem ser entendidas como resultantes da doação intramolecular de electrões $\sigma \mathrm{C}$-H para o metal que está insaturado do ponto de vista electrónico (apenas 12 electrões) e coordenativo (apenas 5 ligações). 0 esperado enfraquecimento da ligação $\mathrm{C}-\mathrm{H}$ agóstica resultante desta interacção, traduz-se num aumento do seu comprimento (5$10 \%$ mais longa) numa diminuição da sua energia da vibração de extensão C-H (nas ligações $\mathrm{C}\left(\mathrm{sp}^{3}\right)-\mathrm{H}$....M 0 valor observado é de $2700-2350 \mathrm{~cm}^{-1}$ em vez dos habituais $2900 \mathrm{~cm}^{-1}$ ) e na diminuição da constante de acoplamento $\mathrm{J}\left({ }^{13} \mathrm{C}-{ }^{1} \mathrm{H}\right)$ nos espectros de RMN (nas ligações $\mathrm{C}\left(\mathrm{sp}^{3}\right)$ -

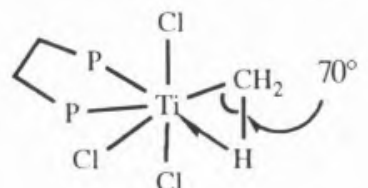

6

dacoda; 1.5-diazaciclooctano-N,N'-diacetato
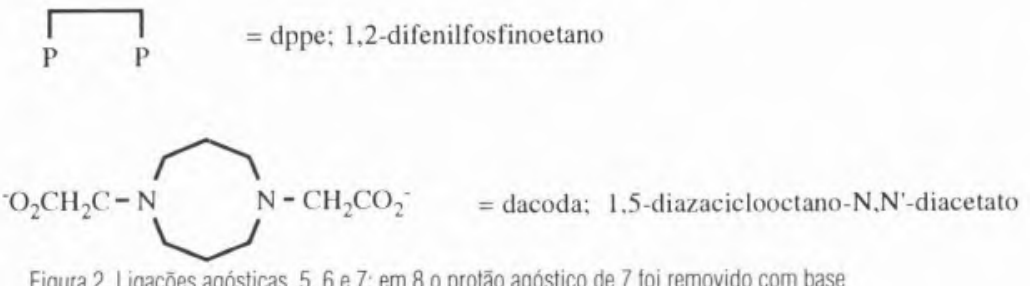

Figura 2. Ligaç̄ôs agósticas, 5, 6 e 7; em 8 o protāo agóstico de 7 foi removido com base

H...M observam-se 75-100 Hz em vez dos habituais $120-130 \mathrm{~Hz}$ ). Deste modo, as ligações agósticas podem ser consideradas como autênticos estados de transição congelados da cisão concertada da ligação C-H e um estudo sistemático das respectivas distâncias e ângulos permite concluir que a cisão só se dá quando a distância do metal à ligação é muito curta. ${ }^{1 c}$ Assim, para além da vantagem termodinâmica que pode constituir, o baixo impedimento estereoquímico de $L_{n} M$ é absolutamente essencial para a formação do complexo $\sigma, L_{n} M-\left(\eta^{2}-C-H\right)$. A fácil desprotonação da ligação agóstica de 7, em meio aquoso, para dar $8,{ }^{7}$ apenas vem sublinhar a importância do complexo $\sigma$ na remoção de $\mathrm{H}^{+}$da ligação C-H, em sintonia com a activação de $\mathrm{H}_{2}$.

\section{ANTECEDENTES DA ACTIVAÇÃO C-H ORGANOMETÁLICA}

Os factos e conjecturas da secção anterior estabelecem um quadro bastante nítido das estratégias a seguir para obter exemplos claros e úteis de activação C-H. Todavia, no início dos anos 80 , esta reacção era já conhecida em química organometálica embora não existissem exemplos claros e de alto rendimento/selectividade a nivel intermolecular. De facto, a apetência de determinados centros metálicos para a formação das ligações agósticas, mais não veio do que justificar a facilidade da reacção de ciclometalação, eq.(10), a versão intramolecular de activação $\mathrm{C}-\mathrm{H}$, actualmente muito bem estudada. ${ }^{8} 0$ primeiro exemplo deste tipo de reacção data de 1963 e está representada na eq.(11).

Particularmente frequente é a activação intramolecular de ligações orto-C$\mathrm{H}$, dos anéis benzénicos da $\mathrm{PPh}_{3}$ coordenada(ortometalação) $\mathbf{9}$.

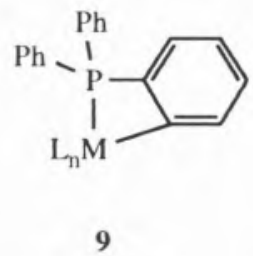

A abundância de exemplos deste tipo de ciclometalações face à raridade das adições oxidativas intermoleculares, é atribuida à vantagem termodinâmica da formação de um metalociclo (efeito de quelação) e chegou a ser tida como praticamente impeditiva da observação destas. Todavia, já em 1965, Chatt havia 

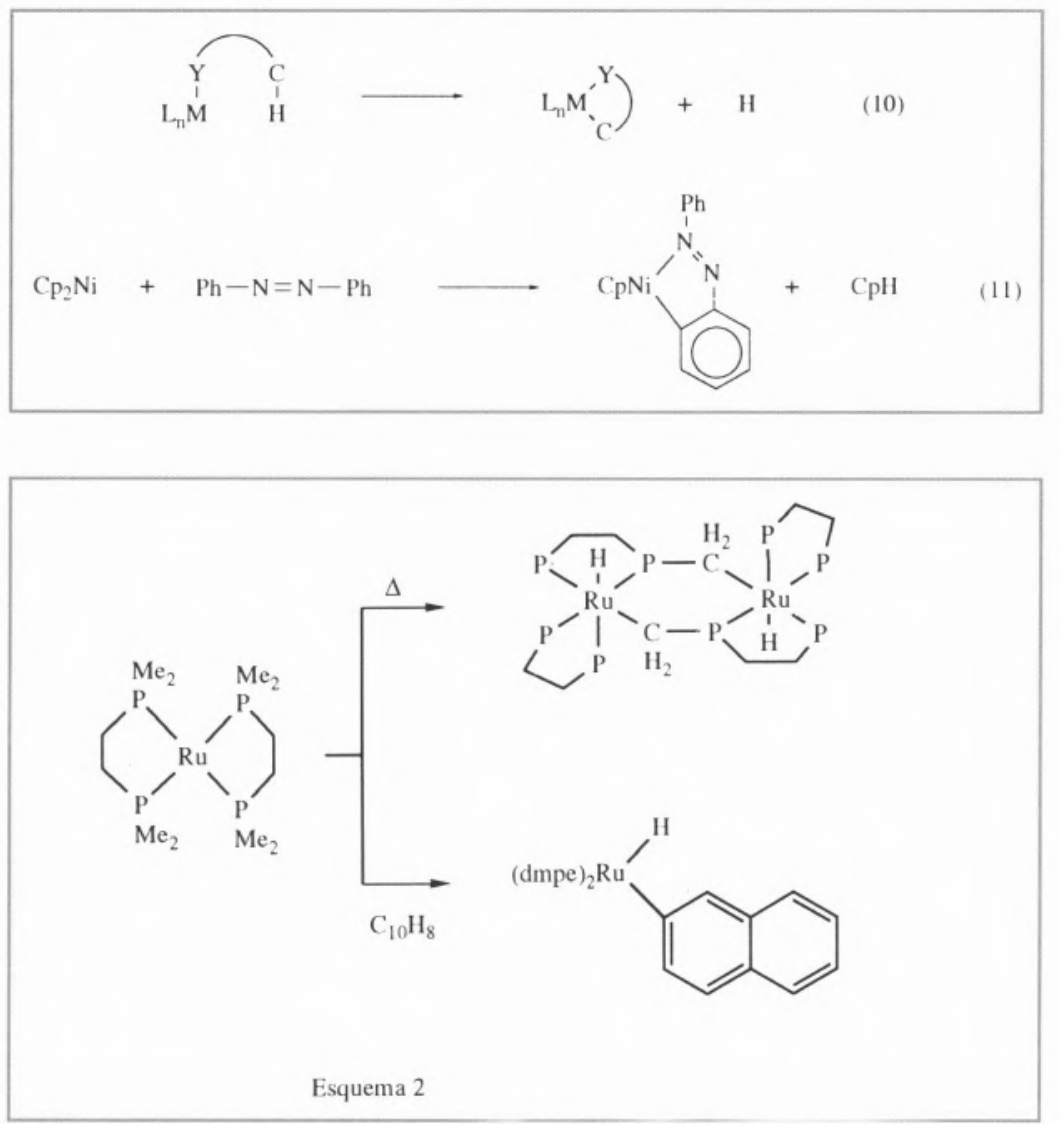

Outro tipo de permuta $H / D$, catalisado por complexos de $\mathrm{M}^{\prime \prime}(\mathrm{M}=\mathrm{Pd}, \mathrm{Pt})$ em meio aquoso ácido, foi o primeiro que mostrou a selectividade areno > alcano $\left(1^{\circ}>2^{\circ}>3^{\circ}\right)$ inversa da observada nas reacções radicalares de activação C-H (orgânicas e bio-inorgânicas). 0 estudo detalhado desta reacção, principalmente levado a cabo por Shilov, revelou tratar-se de um mecanismo de verdadeira activação electrofílica e produziu os primeiros exemplos de funcionalização (cloração) de hidrocarbonetos, como veremos mais adiante.

\section{ACTIVAÇÃO C-H INTERMOLECULAR POR COMPLEXOS ORGANOMETÁLICOS}

\section{Activação C-H por adição oxidativa}

Os primeiros resultados mecanísticamente inequívocos deste tipo de reacção, foram descritos em 1982 de modo quase simultâneo por três grupos independentes, Bergman, Jones e Graham, respectivamente nas eqs.(12), (13) e (14) $\left(\mathrm{Cp}^{\star}=\mathrm{C}_{5} \mathrm{Me}_{5}\right)$.

Os fragmentos organometálicos mostrado a viabilidade de uma competição entre adições intra e intermoleculares, como se mostra no esquema 2.

Por outro lado, resultados como a formação dos compostos $\mathrm{Cp}_{2}$ WHPh e $\mathrm{Cp}_{2} \mathrm{WH}\left(\mathrm{CH}_{2} \mathrm{C}_{6} \mathrm{H}_{4} \mathrm{Me}\right)$ por reacção de " $\mathrm{Cp}_{2} \mathrm{~W}$ " com benzeno ou $\mathrm{p}-\mathrm{C}_{6} \mathrm{H}_{4} \mathrm{Me}_{2}$, obtidos por M. L. H. Green nos anos 70, mostravam que a activação $\mathrm{C}$-H intermolecular era possivel.

Sistemas catalíticos de permuta $H / D$, tendo como percursores polihidretos como $\mathrm{ReH}_{7}\left(\mathrm{PPh}_{3}\right)_{2}$ ou $\mathrm{Cp}_{2} \mathrm{NbH}_{3}$, mostram que a cisão $\mathrm{C}-\mathrm{H}$ também pode ser rápida e catalítica. 0 ciclo de permuta $\mathrm{H} / \mathrm{D}$ catalisado pelo complexo $\mathrm{Cp}_{2} \mathrm{NbH}_{3}$ (ou $\mathrm{Cp}_{2} \mathrm{NbD}_{3}$ ), esquema 3 , mostra a existência de uma competição entre a adição oxidativa de $\mathrm{H}_{2}\left(\mathrm{D}_{2}\right)$ e $\mathrm{C}-\mathrm{H}(\mathrm{C}-\mathrm{D})$ ao centro metálico implicando a semeIhança entre a activação $\mathrm{H}-\mathrm{H}$ e C-H já aludida no plano teórico.

Ainda no domínio da catálise, foram efectuadas reaç̧ões de desidrogenação catalítica, produzindo olefinas a partir de alcanos, usando catalisadores de hidrogenação e condições de remoção de $\mathrm{H}_{2}$. Estas reacções que discutiremos na última secção, mostram a possibilidade real de inverter a eliminação redutiva de alquilohidretos como previsto na eq. (9). ${ }^{9}$
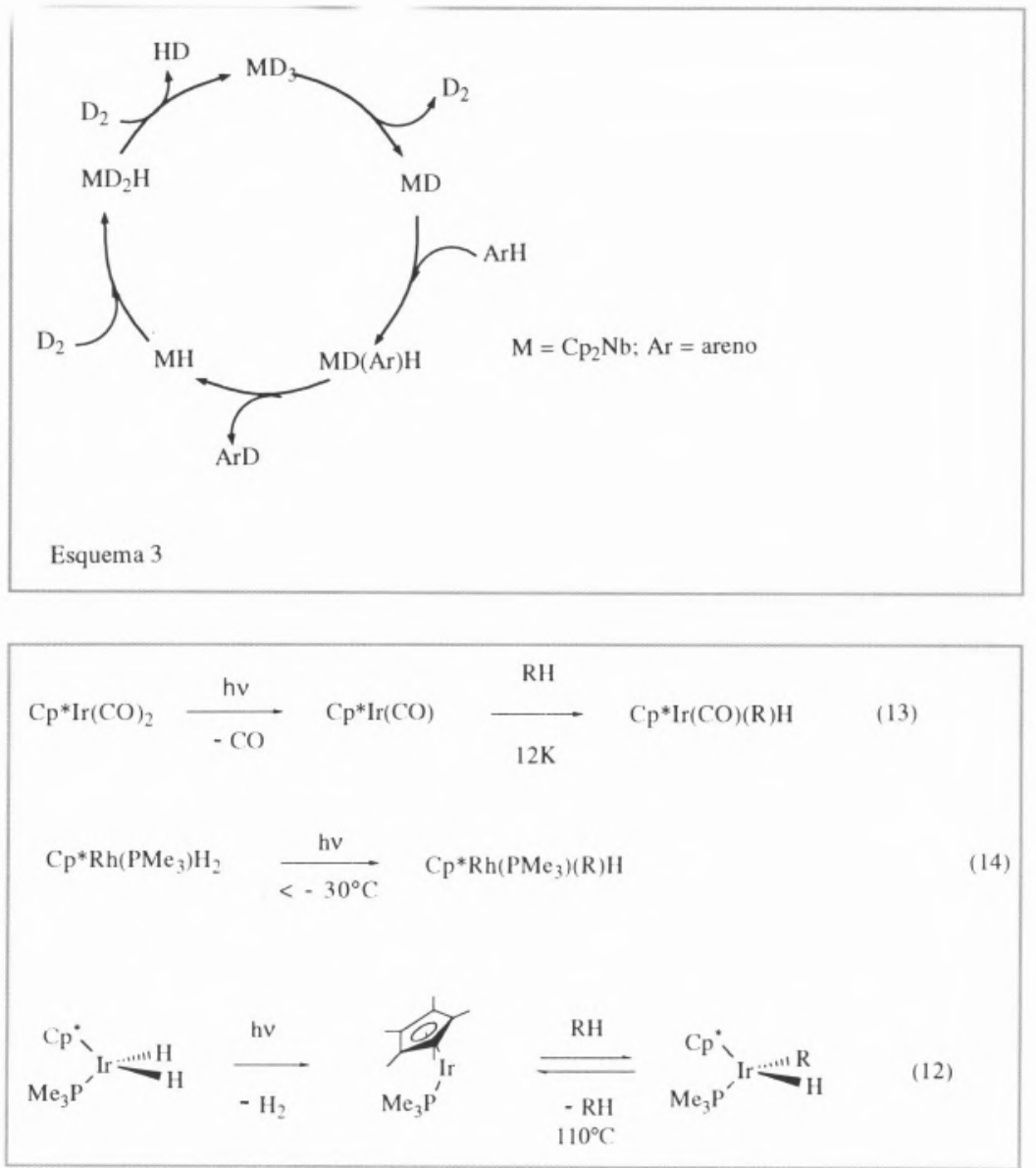
são gerados por fotólise, sendo isoestruturais e isoelectrónicos, apenas com diferenças de metal (Rh ou Ir) e ligandos ( $\mathrm{CO}$ ou $\mathrm{PMe}_{3}$ ). Em consequência do controle termodinâmico destas adições oxidativas, 0 processo de activação $\mathrm{C}-\mathrm{H}$ é mais rápido, nos dois sentidos, para o complexo de Rh dado que as ligações $\mathrm{M}-\mathrm{C}$ e $\mathrm{M}-\mathrm{H}$ são mais fracas para $0 \mathrm{Rh}$ do que para 0 Ir. A baixa energia de activação é posta em particular destaque pela facilidade com que a activação $\mathrm{C}-\mathrm{H}$ tem lugar numa matriz sólida a $12 \mathrm{~K}$. eq.(14). Sendo o mais estável, o sistema $[\mathrm{Ir}]=\mathrm{Cp}{ }^{\star} \mathrm{Ir}\left(\mathrm{PMe}_{3}\right)$ foi 0 mais estudado, mostrando-se no esquema 4 alguns exemplos das suas reacções com diversos substratos.

As ligações $\mathrm{C}-\mathrm{H}$ activadas por este fragmento tanto podem ser do tipo aromático, $\mathrm{C}\left(\mathrm{sp}^{2}\right)-\mathrm{H}$, como alifáti$\mathrm{co}, \mathrm{C}\left(\mathrm{sp}^{3}\right)-\mathrm{H}$ seguindo estas a ordem de selectividade $1^{\circ}>2^{0}>3^{\circ}$. Na realidade, todos os hidrocarbonetos reagem com [Ir] pelo que a utilização de Xénon líquído como solvente inerte, foi muito útil para evitar reacções competitivas $e$ isolar os alquilo-hidretos, $[\mathrm{Ir}](\mathrm{H}) \mathrm{R}$, puros para caracterização analítica e espectroscópica. ${ }^{10}$ As constantes de equílibrio de algumas reacções de competição dão claras indicações sobre a selectividade e os factores que a determinam. ${ }^{11}$ Assim, 0 valor de $\mathrm{K}_{\text {eq }}$ da eq. (15) mostra claramente que a selectividade $1^{0}>2^{0}>3^{0}$ tem uma raiz termodinâmica, do mesmo modo que o valor de $\mathrm{K}_{\text {eq }}$ da eq. (16) põe em relevo a importância do impedimento estereoquímico na estabilidade dos produtos.

De facto, no primeiro caso a competição entre um $\mathrm{C}$ secundário e um $\mathrm{C}$ primário é claramente favorável a este último $\left(\mathrm{K}_{\mathrm{eq}}(15)=10.8 ; \Delta \mathrm{G}^{0}=-2.0\right.$ $\mathrm{Kcalmol}^{-1}$ ) enquanto que no segundo caso $\left(\mathrm{K}_{\text {eq }}(16) \geq 20 ; \Delta \mathrm{G}^{0}=-2.5\right.$ $\mathrm{Kcalmol}^{-1}$ ) ambos os carbonos são primários mas 0 impedimento estereoquímico é bastante diferente e necessariamente menor no derivado com o grupo 'Bu mais afastado do metal. A soma das energias de ligação $\mathrm{D}[\mathrm{Ir}]-\mathrm{H}+\mathrm{D}[\mathrm{Ir}]-$ Cy é da ordem de $135 \mathrm{Kcalmol}^{-1}$ o que confirma as previsões anteriormente mencionadas, de que 0 controle da reacção é termodinâmico e de que só valores de $\mathrm{D}[\mathrm{M}]-\mathrm{C}+\mathrm{D}[\mathrm{M}]-\mathrm{H}>110$ kcalmol-1 $\left([M]=L_{n} M\right)$ podem dar origem a activação $\mathrm{C}-\mathrm{H}$. A reacção descrita na eq. (17) é de $1^{\mathrm{a}}$ ordem em [Ir]-
(H)Cy, e de ordem 0 em PhH.

Inesperadamente, porém, ela também é independente da concentração de $\mathrm{PMe}_{3}$ mas é retardada por excesso de ciclohexano. Esta dependência levou à proposta de mecanismo representada no esquema $5 .{ }^{11}$

$\mathrm{Na}$ caixa do mesmo esquema representa-se 0 mecanismo que permite explicar a permuta H/D observada entre 0 Ir e 0 carbono a ele ligado, $\mathrm{C} \alpha$ (exclusivamente este). Sendo a constante de velocidade desta permuta aproximadamente igual à constante de velocidade da reacção, pode concluirse que o passo controlador da reacção é a descomplexação do ciclohexano do metal. Dito de outro modo, este mecanismo implica a existência de um complexo entre o CyH e o [Ir] cuja dissociação controla a velocidade de reacção com 0 outro hidrocarboneto (PhH neste caso), como já referido no esquema 1.

Os estudos de marcação isotópica do esquema 6 confirmam este tipo de coordenação mostrando a migração do fragmento $[R h]$ ao longo da cadeia alifática. Deste modo, qualquer adição do metal a uma ligação $\mathrm{C}-\mathrm{H}$ secundária, será seguida de rearranjo, com migra-

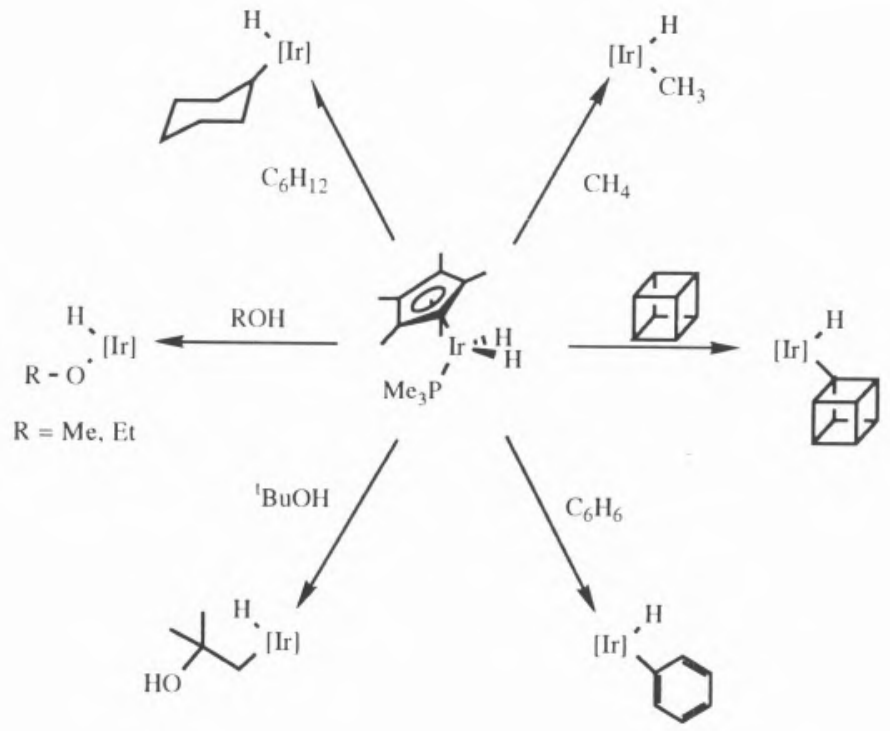

Esquema 4 

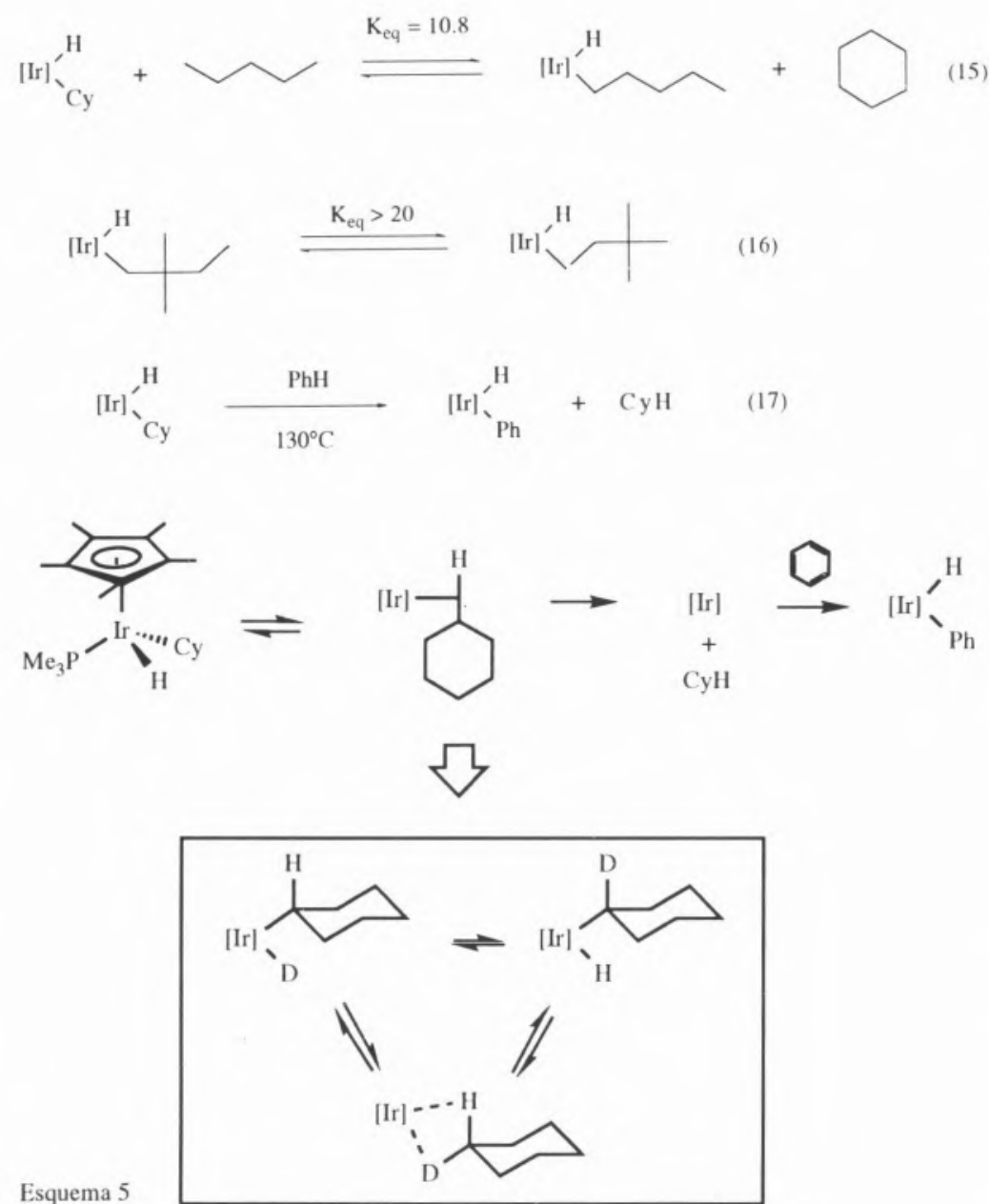

Esquema 5

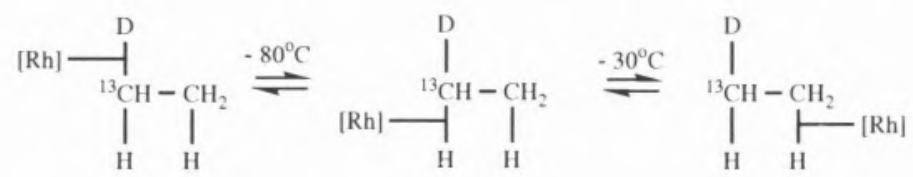

Esquema 6

ção de LnM até chegar à posição termodinâmicamente mais estável, i.e., a um C primário. $^{12}$

No caso dos hidrocarbonetos insaturados, alcenos e aromáticos, a situação pode ser diferente pois a sua núvem $\pi$ pode coordenar-se ao metal. Este pressuposto foi corroborado no caso da reacção de $[R h]$ com benzeno e naftaleno, onde a coordenação do anel ao [Rh] precede a adição oxidativa da ligação C$\mathrm{H}$, eq. (18). ${ }^{13}$ dos, ('PrOH, ${ }^{\mathrm{B}} \mathrm{BuOH}$ ) torna-se mesmo exclusiva. Este facto, simultâneamente importante e surpreendente, deixa entrever a possibilidade de produzir dióis a partir de alcoóis. À partida, este era tido como um dos maiores desafios a vencer no panorama da activação $\mathrm{C}-\mathrm{H}$ pois a inércia reaccional das ligações $\mathrm{C}$ - $\mathrm{H}$ sugeria que qualquer outro substrato reagisse preferencialmente a um alcano. Esta ideia, largamente generalizada entre os químicos organometálicos, é falsa, como se comprova pelo pequeno número de exemplos claros de adição oxidativa de $\mathrm{H}_{2} \mathrm{O}$, alcoóis ou aminas a fragmentos organometálicos, tendo sido induzida pela extrema facilidade de hidrólise de muitos alquilo-complexos $R_{n} M$. Estudos recentes sugerem que, pelo contrário, a adição oxidativa de ligações $X-H(X=C$, $\mathrm{N}, \mathrm{O}, \mathrm{F})$ a um complexo organometálico, é termodinâmicamente análoga em todos os casos e, geralmente, endergónica. Apenas nos casos de complexos com poucos electrões $d$, em que a doação $X(p \pi) \rightarrow M(d \pi)$ constitui forte reforço da ligação $\mathrm{M}-\mathrm{X}$, é que a adição oxidativa de $\mathrm{N}-\mathrm{H}$ e de $\mathrm{O}-\mathrm{H}$ é mais favorável do que a adição oxidativa de $\mathrm{C}-\mathrm{H}$ a qual não pode ser estabilizada por este tipo de efeito visto os alquilos não disporem de pnp. ${ }^{1 \text { a }}$ De facto, quase todos os complexos $R_{n} M$ facilmente hidrolisáveis são espécies em $d^{0}, d^{1}$ ou $d^{2}$. Nos metais mais à direita da Tabela Periódica, e.g., $d$ ${ }^{6}, d^{8}$, a hidrólise e a adição oxidativa de 0 -H são, pelo menos em muitos casos, menos favoráveis do que a activação $\mathrm{C}-\mathrm{H}$ independentemente do seu mecanismo (cf. secção de funcionalização).

Surpreendente foi também a ausência de ciclometalação como reacção competidora e impeditiva da adição oxidativa intermolecular. A explicação é muito simples e resulta de questões estereoquímicas. Como se disse, uma ligação $\mathrm{C}-\mathrm{H}$ tende a interactuar com um fragmento $L_{n} M$ de topo $\left(L_{n} M\left(\eta^{1}-C-H\right)\right.$ sendo necessário vencer bastante repulsão para atingir o estado de transição para a adição oxidativa C$\mathrm{H} O$ qual é triangular. Se $0 L_{n} M$ for pouco impedido, as ligações $\mathrm{C}-\mathrm{H}$ dos seus próprios ligandos terão pouca tendência a aproximar-se do metal para 0 que necessitariam de uma apreciável distorção (cf. 5 e 6) deixando 0 caminho livre às ligações de outras moléculas para se aproximar e reagir. Pelo contrário, numa situação de grande impedimento, a aproximação ao

$$
[\mathrm{Rh}] ?_{\mathrm{R}}^{-\mathrm{H}} \frac{1)-\mathrm{RH}}{2) \mathrm{PhH}}[\mathrm{Rh}]-\mathrm{Rh}_{-}^{-\mathrm{H}}
$$


metal de ligações $\mathrm{C}-\mathrm{H}$ dos próprios ligandos é inevitável, facilitando a ciclometalação e impedindo a aproximação de outras moléculas a distâncias compatíveis com a formação do estado de transição. Assim, enquanto que os complexosCp ${ }^{\circ}\left(\mathrm{PMe}_{3}\right)$ apenas exibem reacções intermoleculares, $\mathrm{CpRe}\left(\mathrm{PMe}_{3}\right)_{2}$ já apresenta uma competição entre estas reacções e a ciclometalação, como se descreve na eq. (19)..$^{1 c, 8}$

\section{Activação C-H por Metátese da ligação $\sigma$}

A possibilidade de realizar a activação C-H com complexos de metais $d^{0}$ ou $f$, já tinha sido prevista com base na vantagem termodinâmica que as ligações $\mathrm{M}-\mathrm{C}$ e $\mathrm{M}-\mathrm{H}$ apresentam nestes casos. Para além disso, o elevado carácter electrófilo destes compostos também sugere a possibilidade de coordenação de ligações C-H passo fundamental da sua activação. A primeira confirmação destes argumentos surgiu em 1983 com a reaccão degenerada da eq.(20) levada a cabo por Watson.

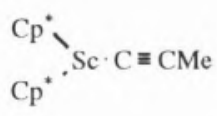<smiles>CC(C)C</smiles><smiles>CCCCCCCCCCCCCCCCC</smiles>

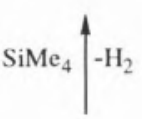<smiles>CCC</smiles>

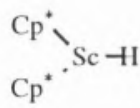<smiles>c1ccccc1</smiles>

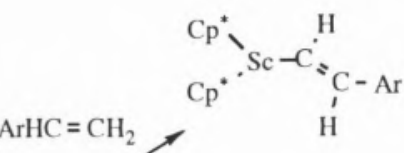<smiles>Cc1cc(C)c(C(=O)c2c(C)cc(C)c(C)c2C)c(C)c1</smiles><smiles>C=CCC</smiles>

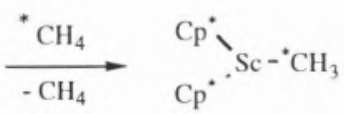<smiles>Cc1ccccc1</smiles><smiles>CCC</smiles><smiles>[Ge][Te]([GeH2])(=[GeH2])c1ccccc1</smiles>

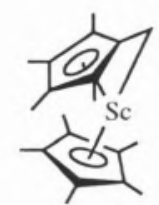

Esquema 7

nos casos de $Y$ e Lu onde está em permanente competição com a adição intermolecular. A lei de velocidades da reacção (21) é de 1ao ordem em [M] e [RH]. A energia de activacão é baixa, $\Delta \mathrm{H}^{*} \sim$ $12 \mathrm{kcal} / \mathrm{mol}$, e a entropia de activação é

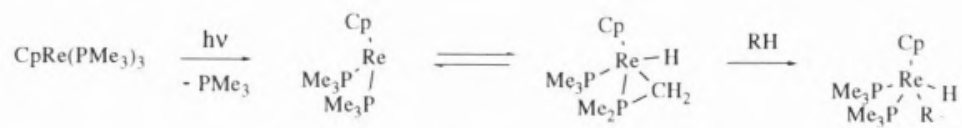

$$
\begin{aligned}
& \mathrm{CP}_{2}{ }_{2} \mathrm{LuCH}_{3}+{ }^{13} \mathrm{CH}_{4} \stackrel{\mathrm{C}_{6} \mathrm{H}_{12}}{\longrightarrow} \mathrm{CP}_{2}{ }_{2} \mathrm{Lu}^{13} \mathrm{CH}_{3}+\mathrm{CH}_{4} \\
& \mathrm{Cr}_{2}{ }_{2} \mathrm{MCH}_{3}+\mathrm{RH}-\stackrel{\mathrm{C}_{6} \mathrm{H}_{12}}{\longrightarrow}{ }_{\mathrm{Cp}}{ }_{2}{ }_{2} \mathrm{MR}+\mathrm{CH}_{4}
\end{aligned}
$$

de -35 u.e., denunciando a existência de um estado de transição altamente ordenado. A ordem decrescente dos valores de $\mathrm{k}_{\text {obs }}, \mathrm{Me}_{4} \mathrm{Si}>$ ciclo- $\mathrm{C}_{3} \mathrm{H}_{6}>\mathrm{CH}_{4}>\mathrm{C}_{3} \mathrm{H}_{8}$ $>\mathrm{CMe}_{4}>\mathrm{CHMe}_{3}$ não se correlaciona com a energia de ligação $\mathrm{D}(\mathrm{C}-\mathrm{H})$ mas sim com a acidez destas ligações na fase gasosa. 0 mecanismo actualmente aceite está representado no esquema 8 . ${ }^{1 a}, 1 c, 15$

Trata-se de um mecanismo multicêntrico no qual as ligações $\mathrm{R}-\mathrm{H}$ e R'H são respectivamente quebradas e formadas de uma forma concertada. É precisamente esta troca de ligações que originou o nome metátese de ligações $\sigma$ para descrever este tipo de activação $\mathrm{C}-\mathrm{H}$. Como estes metais não possuem electrões $d$, não há retrodoação para as orbitais $\sigma^{\star} \mathrm{C}-\mathrm{H}$, pelo que não há adição oxidativa. Trata-se assim de um meca-
Estudos posteriores mostraram a generalidade da reacção intermolecular análoga, eq. (21), para a familia de complexos $\mathrm{Cp}_{2}{ }_{2} \mathrm{MX}(\mathrm{X}=\mathrm{H}, \mathrm{R} ; \mathrm{M}=\mathrm{Y}, \mathrm{Lu}, \mathrm{Sc})$. $A$ ordem decrescente de reactividade $Y>L$ L $>$ Sc na proporcão 250:5:1 é paralela à ordem decrescente de carácter electrófilo, e a selectividade, em termos da ligação $\mathrm{C}-\mathrm{H}$, é $\mathrm{Sp}>\mathrm{Sp}^{2}>\mathrm{Sp}^{3}\left(1^{0}>2^{0}\right)$. Embora menos activo, o complexo $\mathrm{Cp}_{2}{ }_{2} \mathrm{Th}\left(\mathrm{CH}_{2} \mathrm{CMe}_{3}\right)_{2}$ reage de modo semelhante. No esquema 7 mostra-se, para 0 caso do Sc, a variedade de produtos obtida.

A reacção intramolecular de activação de um dos grupos $\mathrm{CH}_{3}$ do anel é lenta no caso do $\mathrm{Sc}$, mas muito rápida

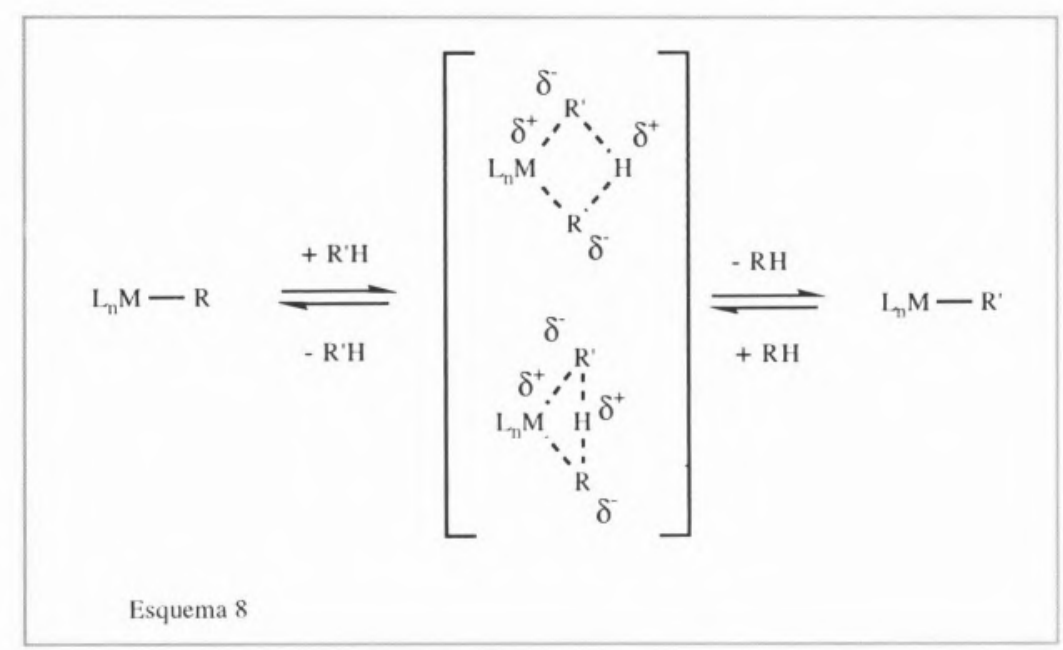


nismo de activação electrófila do tipo ii) (esquema 1) no qual $0 \mathrm{H}^{+}$é removido pelo ligando rejeitado, alquilo ou arilo. 0 estado de transição quadrado, habitualmente usado para descrever reacções de 4 centros, pode não ser 0 mais adequado pois o elevado valor do efeito isotópico cinético da metátese de ligações $\sigma$ $\left(k_{H} / k_{D} \sim 3-5\right)$ parece apontar para um estado de transição onde $0 \mathrm{H}$ se coloca linearmente entre os átomos de $\mathrm{C}$ migrando entre eles por efeito de túnel (esquema 8). Ao contrário do que se observa na activação por adição oxidativa eq. (18), os anéis aromáticos não se coordenam ao metal antes da metátese C-H. Dado o carácter altamente electrófilo destes complexos, a coordenação da núvem aromática geraria um estado de activação do tipo do de Wheland, $\mathbf{1 0}$, típico da substituição electrófila aromática e, como tal, altamente influenciado pela natureza dos substitutintes presentes no anel.

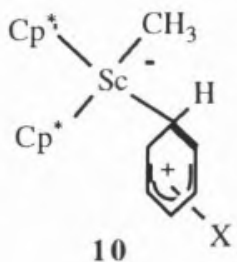

Como a velocidade da metátese de ligações $\sigma$ é independente da natureza dos substitutintes nos anéis aromáticos, pode-se excluir o intermediário 10 e considerar, tal como nos hidrocarbonetos alifáticos, a activação da ligação $\mathrm{C}-\mathrm{H}$ sem intervenção da nuvem $\pi$.

\section{Activação C-H por via electrófila}

A permuta $H / D$ em hidrocarbonetos, catalisada por sais de Pt" em solução aquosa, constitui um dos mais importantes resultados de activação $\mathrm{C}-\mathrm{H}$ por metais de transição e foi objecto de estudo intenso, em particular pelo grupo de Shilov, o qual mostrou que os resultados inicialmente reportados por Garnett e Hodges, referentes à mesma reaccção com arenos, eram extensiveis a alcanos. Tipicamente usa-se $\left[\mathrm{PtCl}_{4}\right]^{2-}$ mas muitos outros sais de $\mathrm{Pt}^{\prime \prime}$ ou Pd" são activos. Do ponto de vista mecanístico a complexidade da reacção é muito maior do que nos casos anteriores pois o número de espécies presentes na mistura reaccional é mais elevado e a sua natureza menos clara. Como exemplo das complicações existentes basta referir

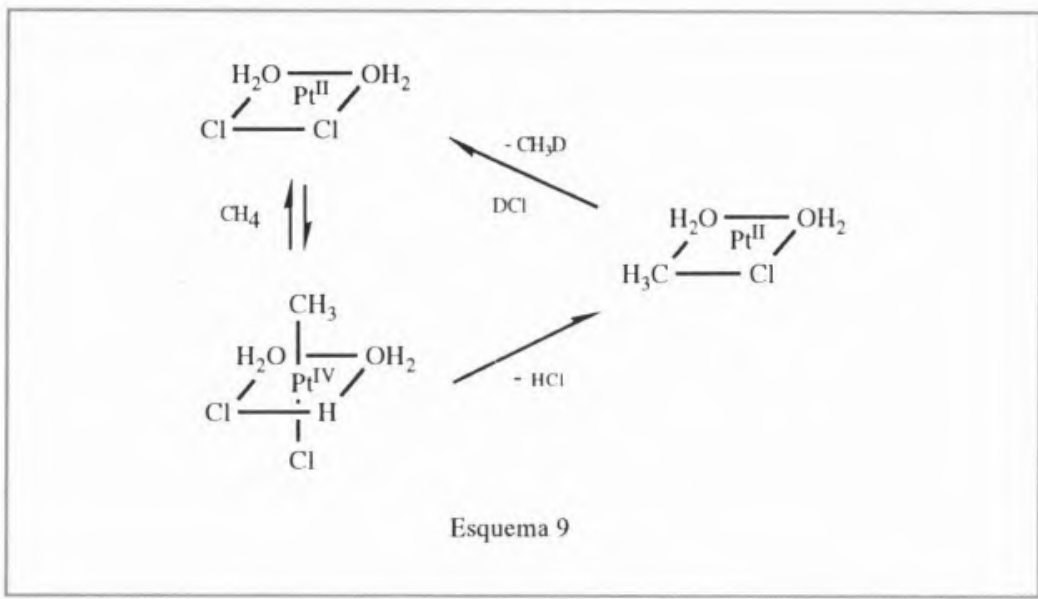

a precipitação de $\mathrm{Pt}^{0}$ durante a reacção a qual pode ser evitada pela adição de um oxidante como $\left[\mathrm{PtCl}_{6}\right]^{2-}$ ou outros. Excesso de $\mathrm{Cl}^{-}$também bloqueia a reacção que se julga iniciada por complexos como $\left[\mathrm{PtCl}_{2}\left(\mathrm{OH}_{2}\right)_{2}\right]$ ou $\left[\mathrm{PtCl}_{3}\left(\mathrm{OH}_{2}\right)\right]$ : Em resultado de muitos estudos cinéticos, Shilov propôs o mecanismo delineado no esquema 9 para 0 caso da permuta $\mathrm{H} / \mathrm{D} \mathrm{em} \mathrm{CH}_{4}$.

A peça fundamental deste mecanismo é a adição oxidativa de uma ligação C-H a um aquo-cloro complexo de $\mathrm{Pt}^{\prime \prime}$ para dar um alquilo-complexo de $\mathrm{P}^{\mathrm{IV}}$. A rápida desprotonação deste complexo (ou a eliminação redutiva de $\mathrm{HCl}$ ) reforma um alquilo-complexo de $\mathrm{Pt}^{\mathrm{H}} 0$ qual pode adicionar $\mathrm{DCl}$ e retornar ao complexo $\left[\mathrm{PtCl}_{2}\left(\mathrm{OH}_{2}\right)_{2}\right]$ por eliminação de $\mathrm{CH}_{3} \mathrm{D}$. Dois entraves principais são levantados a este mecanismo: i) A experiência acumulada na química organometálica de Pt e Pd sugere pouca viabilidade para a adição oxidativa de $\mathrm{CH}_{4}$ (ou quaisquer outras ligações $\mathrm{C}$-H) a complexos de $\mathrm{M}^{\mathrm{II}}$; ii) o mecanismo proposto não acomoda 0 facto experimental de a permuta H/D ser múltipla, i.e., de haver mais do que uma troca $H / D$ por cada encontro catalisador / substrato. Para explicar este último facto foi mesmo proposta a existência de intermediários carbénicos do tipo $\mathrm{Pt}=\mathrm{CH}_{2}$ que não estão previstos neste mecanismo e para os quais não há qualquer evidência experimental. Recentemente, Labinger propôs um mecanismo alternativo ao de Shilov, representado no esquema $10 .^{16}$

A diferença fundamental entre os dois mecanismos reside na natureza da interacção entre 0 hidrocarboneto e 0 centro metálico que deixa de ser uma adição oxidativa para passar a ser uma simples coordenação, seguida de desprotonação, de acordo com 0 mecanismo electrófilo do tipo ii) (esquema 1). A desprotonação do complexo $\mathrm{LnPt}\left(\eta^{2}-\mathrm{H}\right.$ $\mathrm{CH}_{3}$ ) é conseguida por uma base fraca existente em solução $\left(\mathrm{H}_{2} \mathrm{O}, \mathrm{Cl}^{-}\right.$, acetato,...). Em meio ácido $\left(\mathrm{D}^{+}\right)$este passo é facilmente reversivel formando $\operatorname{LnPt}\left(\eta^{2}\right.$ D- $\mathrm{CH}_{3}$ ), o qual pode equilibrar com $\mathrm{LnPt}\left(\eta^{2}-\mathrm{H}-\mathrm{CH}_{2} \mathrm{D}\right.$ ) (cf. caixa do esquema 5) e, por repetição do processo anterior, conduzir a $\operatorname{LnPt}\left(\eta^{2}-\mathrm{D}-\mathrm{CH}_{2} \mathrm{D}\right)$, explicando deste modo a múltipla permuta H/D.

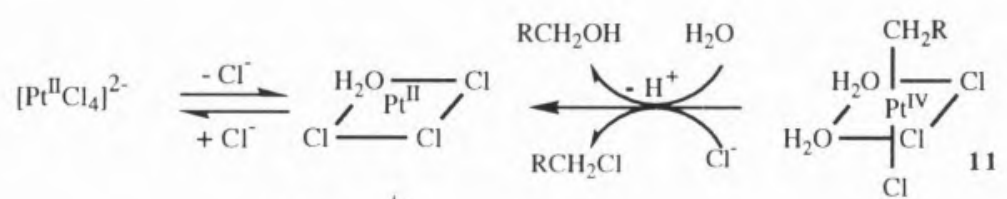<smiles>[R]CC1CC1C=C</smiles><smiles>[R]CC(Cl)OP(Cl)Cl</smiles>

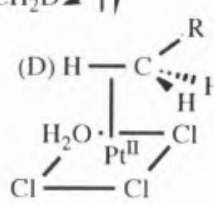


0 aparecimento de Pd ou Pt metálico no decurso da reacção é explicado pela decomposição do alquilo-complexo 11 cuja química determina a capacidade que este sistema possui de permitir a funcionalização catalítica de hidrocarbonetos a alcoóis ou cloretos, abordada na secção seguinte.

\section{FUNCIONALIZAÇÃO DE HIDROCARBONETOS}

0 principal interesse prático da activação C-H é a funcionalização de hidrocarbonetos, em particular a dos alcanos, mais abundantes mas menos reactivos. Se examinarmos 0 Quadro 1 , concluiremos que, após a cisão $\mathrm{C}-\mathrm{H}$, a funcionalização do hidrocarboneto é conseguida à custa de subsequentes transformações da recém-formada ligação $M-C$ as quais, por sua vez, dependem da natureza do complexo resultante da activação $\mathrm{C}-\mathrm{H}$. As reacções de inserção de substratos insaturados $(Z=C O$, $\mathrm{CO}_{2}$, etc. no Quadro 1), largamente utilizadas em química organometálica, seriam uma possibilidade óbvia para a transformação dos alquilo-hidretos $L_{n} M(H) R$ obtidos por adição oxidativa. Todavia, devido à excepcional força das ligações M-C e M-H nestas espécies, e.g. $\mathrm{Cp}{ }^{*} \operatorname{Ir}(\mathrm{H}) \mathrm{Cy}$, estas inserções não se verificam ou são muito lentas pois implicam a quebra de ligações $M-C$ no estado de transição. ${ }^{5}$ Contudo, 0 ataque de electrófilos pode resultar em funcionalizações selectivas de carbonos primários como na bromação da eq. (22) que produz exclusivamente $1-\mathrm{BrPr}$ ao contrário do processo radicalar clássico. Como já se discutiu, (vd eq. 9) se as ligações M-C e $M-H$ de um complexo $L_{n} M(H) R$ forem fracas, a adição $\mathrm{C}-\mathrm{H}$ é muito fácilmente reversivel, a menos que se remova $0 \mathrm{H}$. Tal como representado na eq. (23), este processo é o inverso de uma hidrogenação e, consequentemente, deve poder ser catalisado por catalisadores de
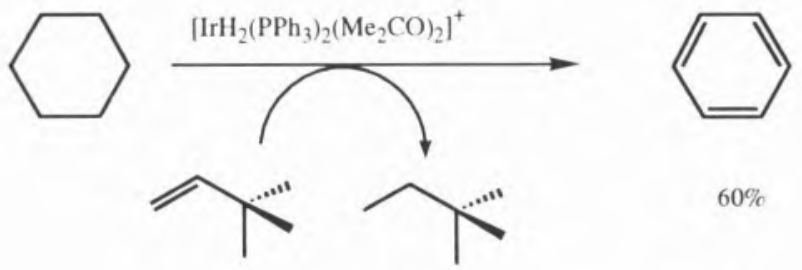

$60 \%$

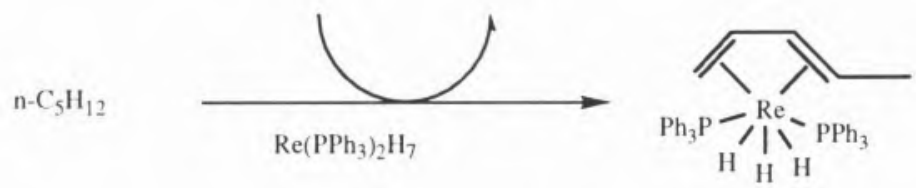

$\mathrm{H} \mathrm{H} H$
Esquema 1

hidrogenação desde que 0 hidrogénio seja removido. ${ }^{17}$

No esquema 11, apresentam-se dois exemplos deste tipo de activação de alcanos por desidrogenação, a qual é extremamente interessante por produzir olefinas, matérias-primas para as quais já existem aplicações tecnologicamente bem estabelecidas. Em ambos os casos o hidrogénio é removido por intermédio da hidrogenação de 'Bu-etileno a qual, sendo particularmente exotérmica, torna 0 processo global termodinâmicamente favorável. Este tipo de reacções pode facilmente ser tornado catalítico sendo os percursores mais usados poli-hidretos como $\mathrm{ReH}_{7}\left(\mathrm{PR}_{3}\right)_{2}, \operatorname{IrH}_{5}\left(\mathrm{PR}_{3}\right)_{2}$, $\mathrm{RuH}_{4}\left(\mathrm{PR}_{3}\right)$ ou $\mathrm{WH}_{6}$ (triphos). $9,17 \mathrm{De}$ acordo com a eq.(23), o catalisador de Wilkinson, $\mathrm{RhCl}\left(\mathrm{PPh}_{3}\right)_{3}$, habitulamente usado para hidrogenar olefinas, é capaz de as desidrogenar desde que, por reflu$\mathrm{xo}, \mathrm{O}_{2}$ seja constantemente removido da reacção.

Estes factos ilustram o controle termodinâmico da activação $\mathrm{C}-\mathrm{H}$ e a baixa energia de activação existente para a adição oxidativa da ligação $\mathrm{C}-\mathrm{H}$ a um metal.

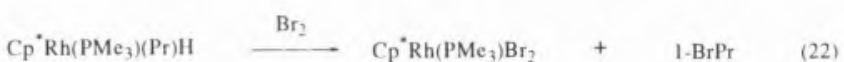

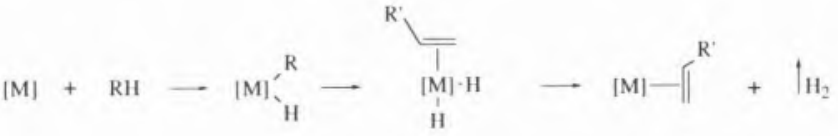
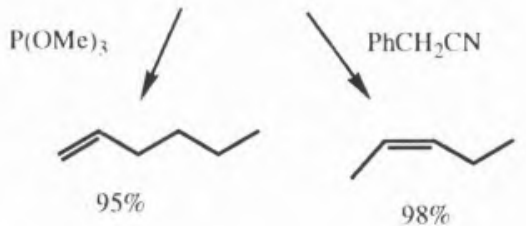

$98 \%$

Todavia, os maiores sucessos de funcionalização de hidrocarbonetos provéem das reacções de ataque electrófilo catalisadas por $\mathrm{M}^{\prime \prime}(\mathrm{M}=\mathrm{Pd}, \mathrm{Pt})$. Em presença de $\mathrm{CF}_{3} \mathrm{COOH}$, estes sais catalisam a formação de $\mathrm{CF}_{3} \mathrm{COOR}\left(\mathrm{R}=\mathrm{CH}_{3}\right.$, adamantilo) a partir de $\mathrm{CH}_{4}$ e adamantano, respectivamente. As primeiras aplicações catalíticas na cloração de arenos e alcanos foram reportadas por Garnett e Hodges e por Shilov nos anos 60 e obtidas nas reacções em que se adicionaram sais de Pt IV (ou outros oxidantes) para evitar a deposição de $\mathbf{M}^{0}(\mathrm{M}=\mathrm{Pd}, \mathrm{Pt})$. No lado direito do esquema 10 representa-se o mecanismo deste tipo de funcionalização, tal como proposto por Labinger para sais de Pt. Após os passos iniciais de activação $\mathrm{C}$-H que já discutimos acima, 0 alquilo-complexo pode ser oxidado, quer por sais de $\mathrm{Pt}^{\|}$quer por sais de $\mathrm{Pt}^{\mathrm{IV}}$, os quais possuem potenciais redox semelhantes. No complexo de $\mathrm{Pt}^{\mathrm{IV}}$ resultante, 0 grupo alquilo (arilo) está fortemente depreciado em electrões pelo que pode reagir com nucleófilos, mesmo fracos, como $\mathrm{H}_{2} \mathrm{O}$ ou $\mathrm{Cl}^{-}$dando origem a alcoóis ou cloroalcanos (cloroarenos), respectivamente. Alquilo-complexos deste tipo já foram isolados destas reacções. Uma das caracteristicas mais interessantes deste método é o facto de se poderem funcionalizar ligações $\mathrm{C}-\mathrm{H}$ primárias na presença de grupos hidroxilo sendo possível produzir 2-cloroetanol ou etilenoglicol a partir de etanol. Embora prometedores, todos estes resultados são ainda incipientes do ponto de vista de aplicações catalíticas pois o número de ciclos catalíticos obtidos é normalmente muito pequeno. 
Todavia é de prever que, uma vez estabelecidas e compreendidas as bases mecanísticas em que assenta a química da activação $\mathrm{C}-\mathrm{H}$, o desenvolvimento de processos catalíticos e outras aplicações económicamente viáveis seja apenas uma questão de tempo. 0 desenvolvimento de catalisadores resistentes à degradação perante espécies capazes de activar ligações $\mathrm{C}-\mathrm{H}$ parece ser 0 ponto mais importante e difícil de resolver.

\section{ACTIVAÇÃO C-H POR VIA ORGANOME- TÁLICA: CONCLUSÕES E NOTAS FINAIS}

Sendo considerado um problema de difícil resolução, até ao início dos anos 80 , a activação C-H por via organometálica revelou-se possível através de sucessivas aproximações teóricas e experimentais actualmente racionalizadas com base em argumentos de natureza teórica (orbitais moleculares) e termodinâmica (energias de ligação). As famílias de fragmentos $C p{ }^{*} M L(M=R h, I r)$ e $\mathrm{Cp}_{2}{ }_{2} \mathrm{MR}(\mathrm{M}=\mathrm{Y}, \mathrm{Lu}, \mathrm{Sc}$ ) produziram os primeiros exemplos de bona fide e mecanisticamente inequivocos, de adição oxidativa $\mathrm{C}-\mathrm{H}$ reversível e de metátese da ligação $\sigma$, respectivamente. A activação electrofilica com sais de Pd" e Pt", de descoberta anterior e pioneira na funcionalização de alcanos e arenos, foi posteriormente integrada no mesmo quadro mecanístico proporcionado pela descoberta dos complexos de $\mathrm{H}_{2}$ e das ligações agósticas, tal como resumido no esquema 12.

No centro destes mecanismos não radicalares está a coordenação da ligação C-H ao metal formando um complexo $\sigma$ cuja evolução é ditada pela natureza do fragmento $L_{n} M$ : adição oxidativa se ele dispuser de orbitais $d$ de energia e simetria adequada $(A)$; metátese da ligação $\sigma$ para fragmentos $d^{0}$ ou $f$, com um bom grupo rejeitado (normalmente alcano) (B); desprotonação, se o centro metálico for simultâneamente macio e electrofílico, como é reconhecidamente 0 caso dos complexos de Pd" e Pt" (C). É também claro que algumas das condições tidas como necessárias para facilitar a cisão $\mathrm{C}-\mathrm{H}$ são naturalmente verificadas nos sistemas activos descritos. Em particular, refere-se 0 seu pequeno impedimento estereoquímico e a elevada energia das suas ligaçõe $\mathrm{M}-\mathrm{C}$ e $\mathrm{M}-\mathrm{H}$.

Os exemplos citados neste artigo não são os únicos capazes de fazer activação $\mathrm{C}-\mathrm{H}$, e muito menos permuta $\mathrm{H} / \mathrm{D}$,

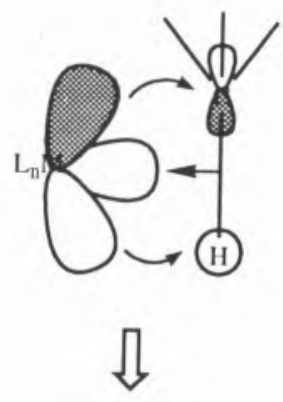

$\mathrm{L}_{\mathrm{n}} \mathrm{M}^{-\mathrm{R}}$

(A)

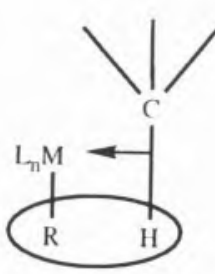

$\sqrt{ }$

$\mathrm{L}_{\mathrm{n}} \mathrm{M} \cdot \mathrm{C}+\mathrm{RH}$

(B)
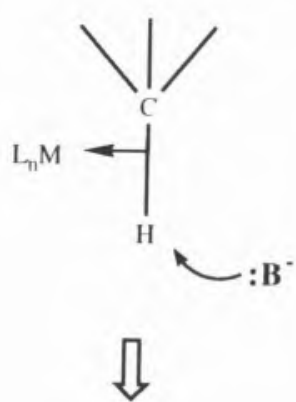

$\mathrm{L}_{\mathrm{n}} \mathrm{M}-\mathrm{C}+\mathrm{BH}$

(C)

Esquema 12

mas são os mais relevantes e bem estudados do ponto de vista mecanístico permitindo portanto um retrato mais nítido do estado actual do problema. De facto, dentro das limitações termodinâmicas do mecanismo $(A)$, vários fragmentos de carácter "pseudo carbénico", i.e., isolobais com $\mathrm{Cp}$ "IrL (mesmo tipo de orbitais fronteira), são activos. ${ }^{1}$ Muitos outros serão certamente desenvolvidos. Por outro lado, mecanismos electrofílicos do tipo (C) são utilizados por diversos metalo-enzimas, ${ }^{1 \mathrm{a}}$ sendo natural que a sua modelação inorgânica venha a produzir resultados interessantes tal como tem acontecido no caso da modelação do citocromo P-450. Do ponto de vista da funcionalização cataliti$\mathrm{ca}, 0$ aspecto central é o desenvolvimento de complexos activos suficientemente resistentes à degradação química para possuirem actividade catalitica de longa duração.

\section{BIBLIOGRAFIA}

*IST E ITQB

1.a) J. A. Davies, P. L. Watson, J. F. Liebman e A. Greenberg, "Selective Hydrocarbon Activation, Pinciples and Progress", VCH Publishers, Weinheim, 1990. b) "Activation and Functionalization of Alkanes", C. L. Hill, Ed., John Wiley \& Sons, New York, 1989; c) R. H. Crabtree, Chem. Rev. 1985, 85, 245-269; d) D. H. R. Barton, J. Boivin e P. Le Coupanec, J. Chem. Soc., Chem. Commun., 1987, 1379-1381; e) C. A. Muedas, R. R. Ferguson, S. H. Brown e R. H. Crabtree, J. Am. Chem. Soc., 1991, 113, 2233-2242.

2.a) G. L. Kubas, Acc. Chem. Res., 1988, 21, 120128; P. G. Jessop e R. H. Morris, Coord. Chem. Rev., 1992, 121, 155-284.

3. J. A. M. Simões e J. L. Beauchamp, Chem. Rev 1990, 90, 629-688.
4. J. Halpern, Inorg. Chim. Acta, 1985, 100, 41-48.

5. J. P. Collman, L. S.Hegedus, J. R. Norton and R. G. Finke, "Principles and Applications of Organotransition Metal Chemistry", University Science Books, 1987, Mill Valley, California.

6.a) M. Brookhart e M. L. H. Green, J. Organomet. Chem., 1983, 250, 395-408; b) R. M. Bullock, C. E. L. Headford, K. M. Hennessy, S. E. Kegley e J. R. Norton, J. Am. Chem. Soc., 1989, 111, 3897 3908.

7. W. E. Broderick, K. Kanamori, R. D. Willett e J. I. Legg, Inorg. Chem., 1991, 30, 3875-3881.

\section{A. D. Ryabov, Chem. Rev., 1990, 90, 403-424}

9. M. L. Deem, Coord. Chem. Rev., 1986, 74, 101125

10. M. B. Sponsler, B. H. Weiller, P. O. Stoutland $e$ R. G. Bergman, J. Am. Chem. Soc., 1989, 111, 6841-6843.

11. J. M. Buchanan, J. M. Stryker e R. G. Bergman, J. Am. Chem. Soc., 1986, 108, 15371550.

12. R. A. Periana e R. G. Bergman, J. Am. Chem. Soc., 1986, 108, 7332-7346.

13. S. T. Belt, L. Dong, S. B. Duckett, W. D. Jones, M. G. Partridge e R. N. Perutz, J. Chem. Soc, Chem. Commun., 1991, 266-269.

14. P. O. Stoutland e R. G. Bergman, J. Am. Chem. Soc., 1988, 110, 5732-5744.

15. a) M. E. Thompson, S. M. Baxter, A. R. Bulls, B. J. Burger, M. C. Nolan, B. D. Santarsiero, W. P. Schaefer e J. E. Bercaw, J. Am. Chem. Soc., 1987. 109, 203; H. Rabaâ, J. Y. Saillard e R. Hoffmann, J. Am. Chem. Soc., 1986, 108, 4327-4333.

16. J. A. Labinger, A. M. Herring, D. K. Lyon, G. A. Luinstra, J. E. Bercaw, I. T. Horváth e K. Eller, Organometallics, 1993, 12, 895-905.

17. T. Aoki e R. H. Crabtree, Organometallics, 1993, 12, 294-298. 